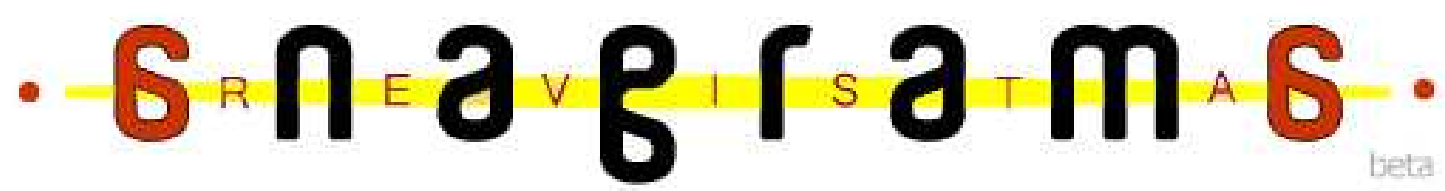

\section{Com Sapatos: calçando uma proposta de treinamento de ator no uniuerso do sapateado}

Stephanie Piva Paranhos ${ }^{1}$

\section{Resumo}

O presente artigo faz uma releitura do treinamento técnico expressivo diário para o ator proposto pelo diretor e pesquisador Luis Otávio Burnier (1956-1995) e o aproxima da técnica do sapateado, de forma que ele se torne tanto estimulo para criação como elemento cênico. O Sapateado é um estilo de dança muito abrangente, no sentido de que o dançarino pode alcançar uma liberdade para transformar, complementar ou compor a forma técnica. E é dentro desta abrangência que pesquisei para identificar pontos possíveis de utilizá-lo no treinamento de ator e que foi concluído com a apresentação do exercício cênico "Com Sapatos", em que o sapateado também foi utilizado como elemento cênico.

Palauras-chaue: Sapateado; Treinamento de Ator, Criação.

O sapateado se desenvolveu através de pessoas que ouviam e observavam uns aos outros na rua, academias e clubes sociais onde passos eram compartilhados, roubados e reinventados. A "técnica" é transmitida através do visual, do corpo e do sentido da audição, como uma troca de ritmos entre dançarinos e músicos. Copiar faz parte para se atingir a maestria da forma (SAMPAIO, CURSO 2007).

Este estilo de dança é muito abrangente, no sentido de que o dançarino pode alcançar uma liberdade para transformar, complementar ou compor a forma técnica. E é dentro desta abrangência que trabalho parte para identificar pontos possíveis de serem

\footnotetext{
1 Atriz graduada no curso de Artes Cênicas pela Universidade Estadual de Londrina. Sapateadora e Pesquisadora da Técnica de sapateado e orientada pela Prof ${ }^{a}$ Ms. Sandra Parra Furlanette durante a dissertação do trabalho de conclusão de curso, cujo foco é o relato da pesquisa durante a experimentação das técnicas de sapateado e o principio técnico de treinamento corporal para o ator e a criação de uma cena em que o sapateado foi utilizado como elemento cênico.
} 
correlacionados ao treinamento de ator.

Em oito anos de aprendizado e mais quatro como professora de sapateado, o que mais me intrigava era a razão pela qual a coreografia era apenas uma coreografia no palco. Depois que entrei no curso de Artes Cênicas, durante as aulas de Expressão Corporal e Interpretação, percebia em alguns exercícios de fortalecimento e aquecimento certa facilidade em executá-los e atribuía esta facilidade aos anos de sapateado na minha vida.

Resolvi montar um pequeno grupo para pesquisarmos juntos as relações entre a execução dos passos de sapateado e as aulas de Interpretação e Expressão Corporal. Este grupo é composto por três integrantes.

Aconteceu por diversas vezes que eu entendesse parte do treinamento de ator sapateando e isto me gerou inquietações.

Por estas minhas inquietações e relações que fiz durante os anos de graduação em Artes Cênicas com o sapateado é que acredito ser possível transpor exercícios de sapateado para o treinamento diário do ator, utilizar a repetição dos passos como estímulo para criação e ressignificar o sapateado em cena.

Eugenio Barba (Brindisi, 29 de outubro de 1936), diretor do grupo Odin Teatret, nos fala em seu livro Além das ilhas flutuantes, de 1991, que o valor do treinamento consiste em autodisciplina cotidiana, personalização do trabalho, demonstração de que se pode mudar, estímulo e efeito sobre os companheiros e sobre o ambiente (BARBA, 1991: $55)$.

Trabalhando e desenvolvendo a pesquisa com este grupo, utilizo como base este conceito sobre o valor do treinamento de que Barba nos fala, traçando um paralelo entre o treinamento de ator e o sapateado.

A prática do trabalho está dividida em duas partes: estudo sobre a contribuição do sapateado como treinamento para o trabalho diário do ator e a ressignificação do sapateado na construção de uma cena. Entendo por ressignificação o fato de utilizar um elemento (seja ele um objeto ou um espaço) e trazê-lo para a cena utilizando-o de forma diferente do que seria geralmente na sua prática cotidiana, fazendo com que este elemento ganhe outro significado. No caso do presente trabalho, o sapateado irá para a cena sem o sentido de uma coreografia hollywoodiana, mas sim, como elemento ressignificado.

A intenção desta pesquisa é semelhante à que Burnier nos coloca no início de seu livro (BURNIER, 2001: 26): Desenvolver um trabalho que me permita fazer uma leitura de 
duas técnicas já existentes e fundi-las, de forma que tenha uma estrutura objetiva e desenvolva a capacidade do ator de articular e modelar os instrumentos de sua arte.

Desde que Stanislavski ${ }^{2}$ começou a pensar em uma sistematização para o treinamento do ator, não nos preocupamos apenas com o ensaio e a representação, mas também com o momento em que o ator se trabalha e aprimora sua técnica. E é neste momento que começamos a falar em técnica para o ator.

Vários diretores e encenadores do teatro elaboraram técnicas para o treinamento do ator. Minha intenção é observar tudo o que absorvi sobre técnica de ator aprendida na Universidade Estadual de Londrina durante meus quatro anos de estudo, na tentativa de fundi-la com a técnica da dança de sapateado, tornando esta técnica mais próxima a mim.

Discípulo do criador da mímica subjetiva, o francês Etienne Decroux, Burnier julgava que os gestos e os movimentos transmitem muito ao espectador e acreditava na potência do movimento. Então trabalhou para libertar o ator da dependência do texto dramático e da própria figura do diretor. Para Burnier, o ator não interpreta, representa. "Não é o ator que está entre o personagem e o espectador, mas o personagem que está entre o ator e o espectador. O intérprete, neste caso, é o espectador" (BURNIER, 2001: 22). Baseado nesses princípios, seu maior legado foi a criação e a codificação de técnicas de representação baseadas na história pessoal e na fisicidade de cada ator.

O treinamento técnico, na visão de Burnier, é abordado de duas maneiras. A primeira e mais conhecida entre nós é o aprendizado via imitação de técnicas corpóreas preestabelecidas, quando o ator aprende uma técnica já codificada ou então trabalha com um conjunto de elementos extraídos de técnicas diversas. A segunda, mais árdua, difícil e demorada, é o desenvolvimento de uma técnica própria e pessoal do ator, partindo-se da premissa de que em cada individuo existe um movimento natural, que pode ser o germe de uma técnica pessoal (BURNIER, 2001: 27).

Concentro-me em sete elementos da ação descritos por Burnier. São eles: a intenção, o élan, o impulso, o acontecimento da ação no tempo e no espaço, o ritmo, a energia e a organicidade. Optei por estes elementos porque são tão fundamentais que estudá-los me permitiu percebê-los tanto no teatro quanto no sapateado.

\footnotetext{
${ }^{2}$ Stanislavski (Moscou, 5 de Janeiro de 1863 - Moscou, 7 de Agosto de 1938) fundou a Sociedade de Arte e Literatura em 1888. Foi diretor e pedagogo de grande destaque dos séculos XIX e XX (GUINSBURG, 1985, p.21).
} 
Burnier nos coloca que a intenção significa "ação de tencionar, tensão, vontade". Apesar de a palavra intenção não ter origem etimológica do prefixo in (em, dentro de), a intenção só existe para o ator na medida em que for corpo, quando existem duas forças opostas criando uma tensão (BURNIER, 2001: 39).

$\mathrm{Na}$ relação que proponho entre treinamento de ator e sapateado, executamos exercícios que trabalham esta tensão de oposição. A maioria das seqüências de sapateado exige que o corpo do sapateador encontre esta oposição para que haja equilíbrio no corpo, mas no nosso grupo trabalhamos dois exercícios especificadamente, que são: Pullback e Toe-drop. Em ambos os passos é necessário que o ator/sapateador dê um impulso para o salto com o tronco, mas mantenha as pernas e pés praticamente no chão para alcançar o som adequado. Gosto de pensar em uma imagem que a professora Thais D'Abronzo utilizava nas aulas de Interpretação II no segundo ano, que era a imagem de céu e terra. É como se você separasse seu corpo em duas partes: do quadril para cima e do quadril para baixo, e no final juntasse as duas partes.

Também incluímos o Flap em nosso treinamento diário devido a uma colocação da professora Thais, na qual ela dizia de que era necessário encontrar o ponto exato entre o relaxamento e a tensão.

Outros passos que proporcionam este trabalho com a tensão muscular de oposição são: série de Brush e seqüência com os pés utilizando os passos Heel/ Shuffle/ Tap/ Heel/ Tap.

Segundo Burnier, é importante sublinhar que toda intenção é filha de uma oposição ou contradição que se manifesta muscularmente no corpo (BURNIER, 2001: 39). Portanto, o que fazemos é partir dos filhos para se chegar aos pais: primeiro trabalhamos a oposição e a tensão no nosso corpo, através de exercícios, para depois ligarmos isto a um elemento externo e conseguirmos a intenção necessária.

Segundo o dicionário Le Grand Robert, élan significa um "movimento pelo qual nós nos lançamos ou nos preparamos para lançar alguma coisa" (BURNIER, 2001: 40). O élan é ação interna, a ponto de sequer poder ser percebido. Esta ação interna é uma mobilização para o impulso. Em filosofia, o termo élan é usado no sentido de algo que é vital, criador, "que atravessa a matéria, diversificando". Ele é próximo do sopro de vida (BURNIER, 2001: 40).

Nas aulas de sapateado, como na maioria das danças, quando vamos iniciar uma seqüência, fazemos uma contagem de quatro tempos, que seria: cinco, seis, sete, oito, e aí 
os alunos sabem que esta é a hora de sair. Nos encontros diários com meu grupo de pesquisa optei por trabalhar com um start point, ou seja: toda vez que vamos iniciar qualquer coisa, seja um passo, uma seqüência, uma combinação ou uma investigação, não fazemos a contagem, mas sim nos observamos e, através da sensação de deslocamento do ar e da respiração, esperamos o tempo exato em que todas iniciarão juntas. Ficamos nos preparando para lançar o corpo no espaço. É também um momento de concentração em conjunto.

É como se meu corpo já fosse dar o primeiro impulso para começar, mas estivesse preso por um fio do qual, para me soltar e iniciar, eu preciso de uma prolongada respiração. Esta respiração causa uma alteração no meu corpo que se dá da seguinte forma: meu corpo está esperando para iniciar o primeiro movimento, mas, em vez disto, ocorre uma oposição e meu corpo vai levemente para trás para depois iniciar aquilo para o que meu corpo já estava preparado.

Burnier nos fala, a respeito do impulso, que este adquire o sentido de empurrar ou arremessar para fora com força a partir do interior. O impulso será utilizado pelo ator logo após ele ter entendido e conseguido criar a intenção de uma ação. Depois que a intenção existir, ela precisará ser arremessada para fora, então o impulso se encarregará disto (BURNIER, 2001: 40).

Os impulsos precedem as ações físicas, sempre. É como se a ação física, ainda invisível do externo, tivesse já nascido no corpo. É isso o impulso. [...] Antes da ação física tem o impulso, que empurra dentro do corpo [...]. Na realidade, a ação física, se não iniciada de um impulso, vira algo de convencional, quase um gesto. Quando trabalhamos com os impulsos, ela fica enraizada no corpo (BURNIER, 2001: 41).

Não haverá ação física sem o impulso, portanto, este se torna fundamental para a criação e execução de uma ação. Podemos pensar o impulso - não somente, mas também como sendo o coração da ação. O coração da ação funciona exatamente como o coração biológico. Não é possível haver vida sem ele. E pensando por esta lógica o coração da ação se encontra no tronco (parte essencial de uma ação).

O impulso não é um elemento fácil de ser conceituado, pois nem sempre é facilmente visível. Mas se pensarmos em nosso dia-a-dia, podemos entendê-lo com clareza. Quando acordamos pela manhã em nossas camas, necessitamos de algo para que possamos nos levantar e ficar de pé. Este "algo" é o impulso. Ou quando observamos uma criança brincando de saltar, antes do salto existe uma mola imaginária que empurra a 
criança para cima. Esta mola imaginária também é o impulso. Portanto percebemos que, para a execução de qualquer ação, seja ela cotidiana ou extra-cotidiana, utilizamos o impulso.

No sapateado é impossível a execução de qualquer passo sem o impulso. Geralmente este arremessar para fora parte do centro do corpo, ou seja, da região abdominal ou da coluna vertebral. O tempo todo partes do corpo são arremessadas pelo espaço, seja uma perna, um pé, os braços, o tronco, a cabeça, o corpo todo a partir do pé. Não importa o quê, o importante é que os passos de sapateado trabalham várias vezes com arremesso. Uma imagem que ajuda nessa execução é pensar que o movimento parte de uma mola imaginária que está embaixo do seu corpo ou da parte do corpo que será lançado. Quando utilizo esta imagem meu corpo reage com um relaxamento da musculatura, cedendo para baixo.

Os passos que mais trabalham o impulso são: seqüência de Toe/ Hop/ Step com deslocamento e meio giro, sequiência de Scuff/ Hop/Step para frente e para trás, Pullback e Toe-drop. Quando trabalhamos juntamente as seqüências Heel/ Hop/ Step (frente) para Toel Hop/Step (trás) e Toe/ Hop/Step (trás) para Step (direita) frente, Step (esquerda) lado esquerdo, Step (direita) atrás, Step (esquerda) centro, temos mudança de sentido várias vezes, e para que haja estas mudanças de sentido é necessário um novo impulso partindo do tronco do corpo, para que, através de oposição e equilíbrio, possa haver uma continuidade dos passos, e não um passo de cada vez.

Burnier também fala que o impulso pode ser sutil e delicado, quase invisível do exterior, que é diferente do seu decorrente movimento (BURNIER, 2001: 40,41). Vivenciei esta experiência quando, na improvisação, me preparava para fazer determinado passo e não o fazia - era como se "fizesse o passo para dentro", ele não chegava a se transformar em movimento visível no espaço. Este impulso gerava uma alteração no meu estado físico e mental, me proporcionando executar aquele passo de forma que minha intenção era modificada. É como se eu me preparasse para fazer um passo que requer agilidade e força, mas, em vez disso, fizesse outro que é aparentemente imóvel; porém, junto com esta aparente imobilidade eu estava com minha musculatura pronta para executar o primeiro passo que requeria agilidade e força. 
De acordo com Burnier, um movimento corpóreo é um deslocamento no espaço e no tempo de partes do corpo. Burnier nos coloca um conceito de Laban $^{3}$ que é de grande valia para o nosso entendimento: o tempo de uma ação corresponde à duração do movimento, e o espaço da ação é o itinerário que o movimento percorre. Não existe movimento que não percorra um itinerário e não tenha um ritmo.

Voltemos a pensar em nosso dia-a-dia: quando atravessamos uma avenida o itinerário em questão é o espaço que percorremos entre uma calçada e outra (neste caso estou analisando uma grande ação que contém pequenas ações, e nós também poderíamos analisar o ritmo por estas pequenas ações); suponhamos que o semáforo esteja verde para os carros, mas o carro mais próximo de nós está a dois metros de distância e venha devagar; atravessaremos este espaço em um tempo mais rápido do que se o semáforo estivesse vermelho para os carros e liberado para os pedestres.

Se o movimento é o deslocamento do corpo no tempo e no espaço, então temos aqui dois componentes importantes que podem ter proporções diferentes, coexistir em suas plenitudes ou não [...] se os impulsos podem acontecer plenamente no tempo, sem quase nenhum movimento no espaço, então também podem acontecer com pequenos e contidos movimentos ou, ao contrário, em um espaço maior, ampliado (FERNANDES, 2000: 14).

Geralmente, no sapateado, trabalhamos com a questão do tempo e do espaço de forma mais imposta. Entendamos este "imposta" como uma opção que fazemos e estabelecemos. Quando estamos trabalhando em uma coreografia, estabelecemos o espaço que os dançarinos percorrerão, e o tempo é dado de acordo com o passo escolhido. Nem sempre o sapateador tem liberdade para explorar todos os níveis, pois é necessário ajustar seu corpo para que as placas do sapato toquem o chão, então geralmente é mais fácil trabalhar no nível alto ou médio do que no nível baixo. Mas, de qualquer forma, cada passo de sapateado percorre um itinerário, seja ele espaçado ou contido.

Uma imagem que sempre me acompanha, quando penso nesta questão do espaço: é como se as plaquinhas do meu sapato tivessem tinta e, conforme elas tocam no chão dentro do espaço que aquele passo tem, elas vão formando um desenho, e isso é influenciado pelo tempo do passo. É como se este desenho imaginário delimitasse o

\footnotetext{
${ }^{3}$ Rudolph Von Laban (1879-1958) usou o termo dança-teatro para descrever a dança como um movimento independente, baseado em "correspondências harmoniosas entre qualidades dinâmicas de movimento e percursos no espaço". Laban criou seu importante sistema de movimento, Tans-Ton-Wort (Dança-TomPalavra) a partir de improvisações. Em suas peças, incorporava movimentos cotidianos e abstratos em forma de narrativas. (FERNANDES, 2000, p. 14).
} 
espaço de execução do movimento. Com este espaço delimitado meu corpo reage com atenção dobrada para que nenhum movimento o ultrapasse ou invada.

No caso do tempo desta ação ou movimento, cada passo de sapateado tem o seu próprio tempo pré-estabelecido; o que se pode fazer é acelerar ou desacelerar, mas aí já estaremos modificando o ritmo. Por haver esta forma imposta e codificada de trabalhar com o espaço e tempo, quando estamos investigando, uma opção é decodificar esta forma imposta para estabelecer uma partitura corporal, de forma a nos proporcionar um arsenal mais variado para esta vivência.

Quando Burnier nos coloca que o ritmo é, sobretudo a pulsação do tempo da ação e de seu movimento (BURNIER, 2001: 45), penso imediatamente em um metrônomo. O metrônomo é muito usado pelos músicos para que, por exemplo, no ensaio de uma banda, nenhum instrumentista perca o tempo/ritmo, mesmo que haja um momento de silêncio na música.

$\mathrm{O}$ ator deve necessariamente entender o ritmo tanto intelectualmente como corporalmente falando. Se houver uma ação e esta ação tiver um intervalo de aparente imobilidade, o ator precisa manter o ritmo da ação, da mesma forma que o músico mantém o ritmo da música em um intervalo de silêncio.

Pensemos mais uma vez em nosso dia-a-dia. Quando executamos uma ação de forma automática como, por exemplo, dirigir (excluindo hipoteticamente todos os outros fatores como atraso, pontualidade, trânsito, pedestres e riscos que estão presentes o tempo todo), dirigimos em um ritmo próprio individual e acelerado, em comparação a quando aprendemos a dirigir e ainda estamos inseguros quanto à execução desta tarefa, e então a realizamos de forma lenta.

Em termos rítmicos, o sapateado é considerado como um instrumento de percussão, portanto a exploração de ritmos é bastante variada. Dentro das formas de compreensão do ritmo temos uma vertente que se dá através da modulação das velocidades, baseada na contração e relaxamento muscular. O sapateado trata desta forma de compreensão por meio dos passos que têm seu próprio ritmo e sugerem uma tensão muscular diferente é que se dá o estudo dos ritmos.

Além de todos os passos ajudarem na compreensão dos ritmos, o que me proporcionou trabalhar os ritmos de forma mais aprofundada foi a execução da combinação. A combinação, que é a junção das seqüências, me permitiu observar o trabalho de espacialidade que influencia no impulso e no ritmo, que na maioria das vezes 
sofre uma mudança brusca. Cada um dos passos descritos no capítulo anterior tem um ritmo e uma direção já pré-estabelecidos. Por exemplo, no caso da seqüência de Flaps, que tem ritmo acelerado e direção para frente e passa direto para o Heel/ Hop/ Step, que é um passo que tem salto e um ritmo quebrado. Esta mudança gera uma necessidade de compreensão e domínio das velocidades de movimento. E é justamente por me ajudar na observação das passagens dos passos que optei por trabalharmos esta seqüência fixa.

É como passar rapidamente pela sensação de quatro elementos diferentes: água, fogo, areia e vento, pois pensando nestes elementos o ritmo do meu corpo se modifica. Quando me deparo com as imagens de água, fogo, areia e vento, tento recuperar a sensação muscular que cada um destes elementos traz em particular: a água, que tem leveza e resistência; o fogo, que tem agilidade ao se espalhar e aquece, dilatando os poros; a areia, que possui mais resistência do que a água e seus grãos, se em grande quantidade, dão a sensação de esfoliação da pele; e por fim o vento, que possui a qualidade de flutuação e rapidez. Então, cada uma destas qualidades gera uma necessidade de ritmo, e é aí que esta imagem altera meu estado corporal.

Se o ator entende o ritmo, ele pode trabalhar com as variações do ritmo de uma ação, favorecendo a intenção da ação.

Burnier nos coloca que todos os elementos componentes de sua ação física analisados acima, ao se relacionarem entre si, criam linhas de tensão, de oposição, contradições, que geram energia (BURNIER, 2001: 50).

A energia está diretamente ligada ao que chamamos de presença de ator. Então podemos pensar a energia como sendo uma vibração que se propaga pelo espaço.

O dicionário inglês Peguin English Dicionary apresenta-a como "poder, força, capacidade de realizar trabalho". Energia está, portanto, associada à sua raiz grega ergein, significando um certo tipo de trabalho, e ao prefixo em, ou interior (BURNIER, 2001: 50).

Um bom exemplo de energia no nosso cotidiano é quando precisamos convencer alguém. $\mathrm{O}$ fato de termos de convencer alguém indica que há uma resistência da outra pessoa em concordar com o fato que colocamos. Esta resistência faz com que tenhamos o trabalho de pensar em argumentos e elaborarmos uma forma de colocar nosso ponto de vista. Na maioria das vezes, saímos cansados deste tipo de conversa. Este cansaço é o desgaste de energia que temos. 
Outra forma de pensar energia é como um ciclo: para que se tenha energia é necessário resistência, que gera trabalho, que por sua vez gera energia.

Burnier coloca que há três formas de adquirir energia relacionadas com a presença do ator, e o sapateado trabalha diretamente com as três formas. A primeira diz respeito aos elementos descritos acima relacionados entre si: isto ocorre no sapateado quando executamos a combinação, que é a junção de varias seqüências; na segunda, na qual ele fala da resistência, que gera trabalho, que por sua vez gera energia: isso ocorre no sapateado quando temos a resistência da placa de metal do sapato com o chão de madeira; e por último ele fala da energia como vibração que se propaga pelo espaço, sendo gerada no sapateado quando já absorvemos a técnica e começamos a nos preocupar com o aprimoramento do som, que se dá com a posição exata dos pés dentro do sapato.

Burnier nos fala que cada um dos movimentos estão no seu devido lugar, pois o corpo pensa por si. No gato não há uma mente discursiva a bloquear a reação orgânica imediata, a criar obstáculos. A organicidade poderia encontrar-se também no homem, mas está quase sempre bloqueada por uma mente que está fazendo o próprio trabalho, uma mente que tenta conduzir o corpo, pensar velozmente e dizer ao corpo o que fazer e como (BURNIER, 2001: 53).

Em outras palavras, o que Burnier nos coloca aqui é que, para atingirmos um grau avançado de organicidade, precisamos desbloquear nossa mente - desconectar nosso corpo das tarefas cotidianas e pensar mais calmamente, deixar que o próprio corpo sinta quais são suas reais necessidades.

Eu compreendo esta colocação de Burnier através da imagem de transbordar e esvaziar. Primeiro você enche a garrafa até transbordar e limpar todos os fluidos e depois permite que tudo se esvazie para começar a encher novamente, mas agora com os princípios técnicos e as imagens que os acompanham. Neste esvaziar acontece um relaxamento do meu corpo e abstração de todo e qualquer tipo de pensamento que possa interferir naquele momento lúdico/cênico.

Durante algumas aulas de sapateado digo a seguinte frase às minhas alunas: "não pensem para fazer, deixem que seus pés pensem e dancem sozinhos". Após ouvir esta frase quase mágica, tenho a impressão de que elas desbloqueiam algumas áreas de suas mentes e se permitem dançar sem tentar fazer "o certo". Às vezes, para dar uma ajuda com este desbloqueio, após lançar a frase coloco uma música com o ritmo bem acelerado para que suas mentes fiquem bagunçadas e simplesmente desliguem. O desbloqueio a partir da 
frase gera esse transbordamento que descrevi logo acima, que por sua vez gera uma corporeidade extra-cotidiana.

O treinamento imagético não existe desacoplado do treinamento técnico, pois a partir do trabalho sobre o movimento surgem involuntariamente imagens que nos levam a não estabilizar o treinamento, e sim transformá-lo até alcançar um significado para aquela imagem que fica explícita no corpo.

Quando estou nos meus ensaios, após sapatear durante muito tempo sem parar é como se eu fosse me esvaziando de pensamentos, vícios corporais e musculatura confortável. Esta imagem surge porque os elementos descritos no capitulo anterior coexistem, e dentro desta coexistência tenho a possibilidade de ultrapassar a barreira formal dos passos de sapateado.

A um determinado ponto da minha pesquisa, o universo de imagens que os elementos me proporcionam, juntamente com esta sensação de esvaziamento quando ultrapasso a barreira formal do sapateado, se deparou com um texto da Clarisse Lispector chamado Águas. Formou-se então um diálogo entre esses três elementos, me impulsionando para a criação a partir do surgimento de uma nova imagem: a de uma a aranha, em uma teia de lembranças.

Para que o sapateado se torne elemento significante causador de tensões, a partir do trecho escolhido do livro da Clarisse Lispector tento encontrar elementos concretos descritos no texto para fazer a junção com os passos que vou cuidadosamente colocando em seqüência. As pessoas geralmente estão acostumadas a ver coreografias espetaculares de sapateado com a valorização do som e ritmo. Mas o que faço agora, neste trabalho de ressignificação, é mergulhar no universo do sapateado para corresponder à sensação do trecho do livro da Clarisse Lispector. Portanto o sapateado, neste caso, sofrerá sempre uma influência dos elementos concretos abstraídos do texto, em um processo de ressignificação, para que o sapatear passe a integrar um novo sistema de referências.

Sendo assim, a ressignificação do sapateado para mim consiste em estabelecer relações entre os elementos teatrais proporcionados pelo treinamento do ator e o vocabulário do sapateado, para que, dessa forma, seja atribuído um novo significado ao sapatear. Significado este que deve ter a função de comunicar-se com o espectador.

Com a apresentação do exercício cênico "Com Sapatos" pude concluir que a utilização da dança específica de sapateado pode contribuir tanto no treinamento como na criação do ator, e também como elemento na construção do texto cênico. 


\section{Referencias Bibliográficas}

BARBA, Eugenio. Além das Ilhas Flutuantes. Campinas: Unicamp, 1991.

BURNIER, Luís Otávio. A arte de ator: da técnica a representação. Campinas: UNICAMP, 2001.

FERNANDES, Ciane. Pina Bausch e o Wuppertal Dança-Teatro: Repetição $e$ Transformação. São Paulo: Hucitec, 2000.

GUINSBURG, Jacó. Stanislavski e o Teatro de Arte de Moscou. São Paulo: Perspectiva, 1985.

LISPECTOR, Clarisse. Água Viva. Rio de Janeiro: Rocco, 1998.

SALES, Flavio e MACHADO, Amália. Tap: A Arte do Sapateado. Rio de Janeiro: Addresses, 2003.

\section{CURSOS ASSISTIDOS PELA PESQUISADORA}

Kika Sampaio, na área especifica de Sapateado, pela Universidade Livre de dança. Em 06/02/07, com a duração de 25 horas/ aulas. 